\title{
Understanding token-based ecosystems - a taxonomy of blockchain-based business models of start-ups
}

\author{
Stefan Tönnissen $^{1} \cdot$ Jan Heinrich Beinke ${ }^{1} \cdot$ Frank Teuteberg $^{1}$
}

Received: 27 July 2019 / Accepted: 7 January 2020 / Published online: 28 January 2020

(C) The Author(s) 2020

\begin{abstract}
Start-ups in the blockchain context generate millions by means of initial coin offerings (ICOs). Many of these crowdfunding endeavours are very successful, others are not. However, despite the increasing investments in ICOs, there is still neither sufficient theoretical knowledge nor a comprehensive understanding of the different types of business models and the implications for these token-based ecosystems. Scientific research equally lacks a thorough understanding of the different business model forms and their influence on collaboration in token-based economies. We bridge this gap by presenting a taxonomy of realworld blockchain-based start-ups. For this taxonomy, we used 195 start-ups and performed a cluster-analysis in order to identify three different archetypes and thus gain a deeper understanding. Our taxonomy and the archetypes can equally be seen as strategic guidance for practitioners as well as a starting point for future research concerning the token-based business models.
\end{abstract}

Keywords Blockchain $\cdot$ Ecosystems $\cdot$ Token-based business models $\cdot$ Collaboration $\cdot$ Taxonomy

\section{Introduction}

Although the start-up community successfully generated on average more than 11.5 million dollars worldwide (bitcoinexchangeguide 2018) by means of Initial Coin Offerings (ICO) in 2018, there is still a lack of understanding about the consequences and implications of these token-based ecosystems. Tokens can be used e.g. for services, data exchange or data purchase. ICOs are typically carried out on a blockchain, which stores data in a decentral network by means of cryptographically secured methods. The participants of this peer-to-peer network build a network of untrusted participants without a central intermediary (Fridgen et al. 2018). About ten years ago, the bitcoin network was the first peer-to-peer network based on blockchain technology. The initial growth of blockchain technology solely came from use cases with

This article is part of the Topical Collection on Potential and Limits of Blockchain Technology for Networked Businesses.

Responsible Editor: Roger Bons

Stefan Tönnissen

stoennissen@uni-osnabrueck.de

1 Osnabrueck University, School of Business Administration and Economics, Katharinenstr. 1, 49069 Osnabrück, Germany different kinds of cryptocurrencies. Thus, this first generation of the blockchain technology focused on cryptocurrencies and is known as Blockchain 1.0. The next generation, Blockchain 2.0, builds on contracts for different industries and offers a broader range of functions. Blockchain 3.0, with significantly wider and more complex applications beyond currencies, is currently emerging (Swan 2015).

Since 2014, the decentralized platform 'Ethereum' has served as a foundation for different kinds of applications with smart contracts. The Ethereum blockchain is a shared global infrastructure enabling start-ups to create markets that can be used all around the world (Ethereum 2018). The currency valid within this infrastructure is Ether, a native cryptographic token on the Ethereum blockchain. Besides, companies can create their own tokens utilizing smart contracts. These are called on-chain tokens, because they operate on top of an existing blockchain. Given the fact that developing and deploying new (simple) applications based on Ethereum by means of an on-chain token is not very complex, many new applications emerged (Fridgen et al. 2018). Glaser (2017) highlighted that the blockchain technology is an innovative technology still searching for use cases. The sale of tokens from entrepreneurs to raise capital is often referred to as Initial Coin Offering (ICO), a means of crowdfunding (Dhillon et al. 2017). According to icodata.com (icodata 2018), more than 1100 ICOs with a total volume of more than 6.9 billion $\$$ were conducted in 2018. The tokens 
created in combination with a blockchain-based platform offer more opportunities than financing the business development of the company, as the token can be used as a separate currency within the platform (Ehrsam 2016). They are an essential part and digital asset of the platform and build the foundation for new kinds of ecosystems. Most of the tokens (so called utility tokens) are used as a currency to pay for the applications offered by the start-ups. Thus, the customers of a respective ecosystem have to use the specific tokens to pay for the service they request, and the contributor or producer of this service receives the tokens as a payment. This closed system works without a central authority. The term platform is also not used consistently and varies between different disciplines like economics or biology (Hein et al. 2018; Evans and Schmalensee 2016; Parker et al. 2016). Current research on business models for the operation of platforms focuses mainly on (a) the economic effects of two-sided or multisided markets, (b) the technical concepts of such software platforms and (c) the mechanisms of governance to organize such platforms (Krcmar and Hein 2018).

The existing literature indicates that blockchain technology can bring about massive changes for business models (Beinke et al. 2018). Nevertheless, token-based ecosystems have attracted little attention in the scientific literature - although the importance of digital ecosystems has increased significantly in recent years. Therefore, it is interesting to get an overview of existing token-based ecosystems. As according to Kar et al. (2018) "each ecosystem represents a solution to a particular challenge to life", we have to distinguish between different business models for token-based ecosystems of start-ups to gain a better understanding. Thus, we aim to answer the following research question (RQ):

RQ: What are the characteristics of business models in token-based ecosystems?

To answer this question, we develop a taxonomy of tokenbased ecosystems. As taxonomies can structure facts and describe relationships between different objects (Glass and Vessey 1995), they have proven themselves in information systems and have become firmly established, e.g. in the area of telemedicine services (Peters et al. 2015) or business models (Remane et al. 2016). Based on the taxonomy, we derive three empirically founded archetypes. On the one hand, these archetypes serve to validate the taxonomy and on the other hand, the classification into a few generic archetypes allows a reduction of complexity and an overview of the main differences in existing token-based ecosystems.

We structured our study as follows: First, we shed some light on the domain background, in particular platforms and token-based ecosystems. Second, we explain our methodological approach to the taxonomy development. Then we develop a taxonomy of start-ups using a token-based ecosystem and derive archetypes. Furthermore, we discuss the implications for research and practice, as well as limitations and present future research opportunities. Our taxonomy will be of value for two user groups: researchers, who analyse the influence of the blockchain technology on business models in general and on the platform economy in particular as well as practitioners, who are planning to transform their former pipeline-business into a platform-business model based on the blockchain technology (Choudary 2015). Furthermore, the taxonomy can help both groups to differentiate all relevant aspects in order to understand and develop a collaborative platform business model for the network economy.

\section{Domain background}

\section{Ecosystems and platform-based businesses}

The word ecosystem is the abbreviation for ecological system (Harris 2017). It defines a community composed of living organisms and non-living components such as air, water, and mineral soil (Chapin et al. 2011). "It is a community of all the components that interact with one another in the same local environment" (Harris 2017). From an economic point of view, there are lots of different definitions and explanations of a so called business ecosystem. Jacobides et al. (2018) characterize ecosystems as an interacting of organizations that are not managed hierarchically, but bound together by the fact that their collective investment cannot be redeployed elsewhere. Moore (1993) rather stresses the cooperation of companies around new innovation with a cooperative and competitive work to support new products. Papert and Pflaum (2017) broaden the definition of the term and describe a business ecosystem "as a community of organisms from the whole business environment, giving consideration to all their relationships". This community of organisms from the business environment "moves from a random collection of organisms to a more structured community" (Moore 1993) whereby its motivation is rather mutual selfinterest than solely individual self-interest (Tham et al. 2017). Peltoniemi and Vuori (2004) define an ecosystem as “.... a dynamic structure which consists of an interconnected population of organizations" (Peltoniemi and Vuori 2004). Selander et al. (2010) argue that ecosystems "are essentially defined by the active shaping of relationships between its members" (Selander et al. 2010). Basole (2009) adds that the success of a platform business model "is inextricably linked to its network, or ecosystem, of enablers and complementors" while Adner (2017) puts the focus on " ...the alignment structure of the multilateral set of partners that need to interact in order for a focal value proposition to materialize...".

Start-ups often face the problem of obtaining external finance through debt capital (Bruton et al. 2015). With the crowdfunding method ICO, start-ups can realize their project (Agrawal et al. 2014; Ahlers et al. 2015) and, through this development, drive new ecosystems based on the issued tokens. 
In our paper, we refer to the various characteristics of the above definitions, which serve as the basis for the taxonomy and represent the distinct perspectives $[\mathrm{P}]$ :

- The ecosystem is the alignment structure of a multilateral set of partners, [P01].

- or a defined period of time, [P02].

- who pursue a common goal, [P03].

- by the active shaping of relationships, [P04].

- to create a common added value for all actors by a focal value proposition. [P05].

The currently prevailing business model is a pipeline business model, in which a company buys raw materials, creates new products, and sells them to customers. In this linear flow of materials, value is added within and between firms (Jacobides et al. 2018). However, the digital transformation is currently bringing other business models to the fore. Platform-based business models, in which each participant creates value for the community on a digital platform, are spreading more and more (Han et al. 2018). Lamarre and May (2017) assume that global ecosystems will be highly customer-centric, made up of different actors offering digitally accessible solutions. Most cited examples of successful platform-based businesses are Alibaba, Apple, Facebook, and Google (Evans and Schmalensee 2016). All these digital platform businesses have in common that they bring together a huge amount of customers with a high amount of companies (Van Alstyne et al. 2016). These platform-based business models are changing the fundamental structures of our economy and maybe even society (Smedlund et al. 2018).

\section{Token-based ecosystems and business models}

In combination with the blockchain technology, the previously described ecosystems and platforms provide various opportunities for new business models (Beinke et al. 2018), whereby each ecosystem can issue its own digital currency (token). With the introduction of the digital currency Bitcoin in 2009, the blockchain technology, which forms the basis for digital currencies, became interesting for new applications and business models. Given its characteristics as a distributed peer-topeer network with no central instance or intermediaries, the blockchain technology provides a suitable basis for platformbased ecosystems. In blockchains, data is stored in blocks that are connected to each other in a way that reflects the course of transactions like a chronological chain (Tönnissen and Teuteberg 2018). Because of the transparency and distributed nature of the blockchain technology, ownership can be transferred from one party to another without the need for a trusting intermediary (Brandon 2016). These ownerships on the basis of the blockchain are often referred to as digital tokens (Fridgen et al. 2018). Digital tokens can be used as a value unit that an ecosystem creates "to self-govern its business model, and empower its users to interact with its products, while facilitating the distribution and sharing of rewards and benefits to all of its stakeholders" (Mougayar 2017).

This new funding method is referred to as an ICO. A coin in this context symbolizes the cryptocurrency which has its own independent blockchain while a token is generated upon on an existing blockchain (Park and Yang 2018, Chanson et al. 2018, Oliveira et al. 2018). Most tokens are based on the Ethereum blockchain and are issued by smart contracts (Chanson et al. 2018). An Ethereum based ICO is often referred to as initial token offerings or tokensale. In this paper, we use the terms initial coin offering, tokensale, and initial token offering synonymously, since the differences are negligible from an ecosystem perspective. Since the issued tokens can offer several added values, we emphasize their features in the context of a token-based ecosystem (Oliveira et al. 2018). First of all, tokens can be used to transfer value between business partners in the ecosystem (Pilkington 2015), for a unit of account (Conley 2017) or storage of wealth (Wenger 2016). Second, the use of tokens can incentive people to use a specific service managed via the blockchain (Wenger 2016). Third, tokens enable the community of an ecosystem to achieve network effects. The major goal is to incentive the early adoption of the token in order to reach a critical mass of users. Lastly, the tokens issued serve to finance the issuing company (Chen 2018).

Basically, there are two ways to perform an ICO. The first option is to develop your own blockchain with your own coins. This entails the advantage that the system can be adapted to special requirements. However, as it is especially difficult and expensive for small companies and startups to set up own, highly complex blockchains, most ICOs are based on the second option, which is to generate own tokens on an existing blockchain such as Ethereum. The advantages of this option are the simple and fast implementation, partly due to the standard ERC20 (Ethereum Request for Comment) for the configuration of tokens. However, the limited functionality of Ethereum (EYGM Limited 2018) is a disadvantage. Currently, tokens are differentiated according to different types and purposes. The most common is the "usage token", which gives the owner access to a digital service. The "work tokens" allow the user to participate in a project, and "funding tokens" are generated for purely financing purposes. Due to the high regulatory requirements, "staking tokens" with co-determination rights and profit entitlements are rather rare (Brennecke et al. 2018). Chanson et al. (2018) distinguish the utility of tokens in three core components. The first core component is the ability to transfer value by exchanging coins with others. The second is the tokens' ability to access a service from the token-based economy by paying a fee in the native 
coin. The third is to share profit between the token-based economy and the token holders (Chanson et al. 2018). Common to the various tokens is the ability to trade in fiat currencies or other cryptocurrencies at exchange portals on the Internet.

In order to also consider the distinctive features of tokens, we supplement our definition attempt of token-based ecosystems with the following perspective.

- using tokens as the value proposition of the ecosystem (P06).

Therefore, our definition of a token-based ecosystem is as follows:

A token-based ecosystem is the alignment structure of a multilateral set of partners for a defined period of time who, through the active shaping of relationships, pursue a common goal of creating common added value for all actors through a central value proposition with tokens as the value proposition of the ecosystem.

\section{Research method}

The advantage of classifying objects in a taxonomy is that properties of a phenomenon can be identified and used as a tool for comparing and contrasting classes (Gregor 2006). Nickerson et al. (2013) state that the classification of objects is a fundamental challenge in many disciplines and the development of a taxonomy is a complex process. Thus, a taxonomy can help researchers and practitioners to understand a complex domain (Nickerson et al. 2013). It structures or prepares the complexity of a certain field of knowledge (Eickhoff et al. 2017), in order to "facilitate systematic research into the differences among, and the need of, particular domains" (Glass and Vessey 1995). Thereby, the taxonomy should allow full classification and include mutually exclusive categories (Glass and Vessey 1995). In a formal presentation, the taxonomy $(\mathrm{T})$ is "a set of dimensions $\left(\mathrm{D}_{\mathrm{i}}\right)$ each consisting of a set of mutually exclusive and collective exhaustive characteristics $\left(\mathrm{C}_{\mathrm{ij}}\right)$ " (Nickerson et al. 2013). The formal presentation of a taxonomy is as follows:

$T=\left\{D_{i}, i=1, \ldots n \mid D_{i}=\left\{C_{i j}, j=1, \ldots k_{i} ; k_{i} \geq 2\right\}\right\}$

The entire research process is shown in Fig. 1.

We started the development of our taxonomy by means of a literature review following the guidelines of Webster and Watson (2002). For the search we used the databases emerald insights, ACM Digital Library, Web of Science, EBSCOhost and the terms "taxonomy and blockchain OR distributed ledger OR start-up" and included a forward and backward search. At the end we could select 72 publications. An examination based on the title and the abstract led us to the following relevant contributions (see Table 1). In a next step, we determined the meta-characteristics relevant to determining the objects of interest (Nickerson et al. 2013). Our metacharacteristic is the focus on the new token-based ecosystems as well as the ways in which the multiple parties cooperate and create value in this ecosystem.

For the second phase, we follow an iterative empirical-toconceptual approach for which we need objective and subjective ending conditions to determine the end. The objective ending conditions for our approach were that (a) all objects have been examined, (b) no new dimensions or characteristics were added and (c) no dimensions or characteristics were merged or split (Nickerson et al. 2013). Subjective ending conditions for the development of a taxonomy according to Nickerson et al. (2013) should be concise, robust, comprehensive, extendible, and explanatory. As a taxonomy is considered concise if the taxonomy with its dimensions and characteristics does not "exceed the cognitive load of the researcher", the number of dimensions and characteristics should be limited. On the other hand, a taxonomy should be robust with "enough dimensions and characteristics to clearly differentiate
Fig. 1 The taxonomy development process based on Nickerson et al. (2013)
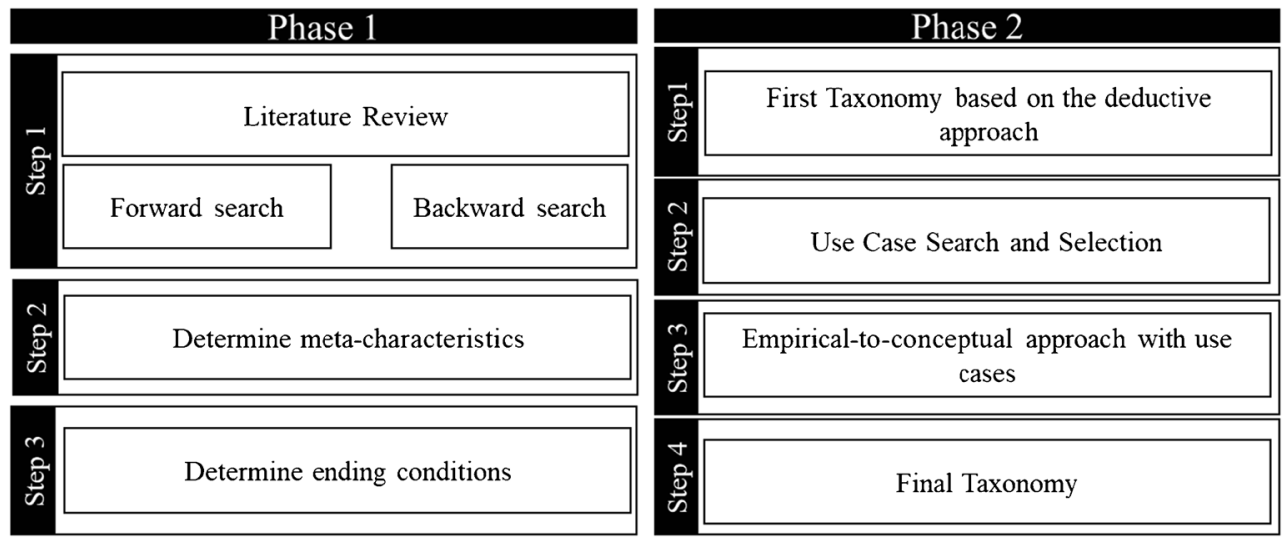
Table 1 Relevant papers to blockchain, taxonomies, start-ups, and derived dimensions

\begin{tabular}{|c|c|c|c|}
\hline Title & Author & Year & Dimension \\
\hline $\begin{array}{l}\text { Don't slip on the initial coin offerings (ICO) - } \\
\text { A Taxonomy for a blockchain-enabled } \\
\text { form of crowdfunding. }\end{array}$ & Fridgen, G. et al. & 2018 & Token purpose/type \\
\hline $\begin{array}{l}\text { The entrepreneur's business model: Toward a } \\
\text { unified perspective }\end{array}$ & Morris et al. & 2005 & Customer segment \\
\hline $\begin{array}{l}\text { Investing in tokens and decentralized business } \\
\text { models }\end{array}$ & McKie, S. & 2017 & Types of decentralized business models, Associate \\
\hline Matchmakers & Evans, D. S.; Schmalensee, R. & 2016 & Market types, Network effect \\
\hline Predators and Prey & Moore, J. F. & 1993 & Stage of Business Ecosystem \\
\hline $\begin{array}{l}\text { A European agenda for the collaborative } \\
\text { economy }\end{array}$ & European Commission & 2016 & Level of Control \\
\hline A Taxonomy of Supply Chain Collaboration & Simatupang, T. M. & 2007 & Collaboration \\
\hline $\begin{array}{l}\text { Decentralized Blockchain-Based Electronic } \\
\text { Marketplaces }\end{array}$ & Subramanian, $\mathrm{H}$. & 2018 & Increase network effects \\
\hline $\begin{array}{l}\text { Tokenomics - A business guide to token } \\
\text { usage, utility and value }\end{array}$ & Mougayar, W. & 2017 & Token incentive \\
\hline $\begin{array}{l}\text { Towards a Business Model Taxonomy of } \\
\text { Startups in the Finance Sector using } \\
\text { Blockchain. }\end{array}$ & Beinke, J. H.; Nguyen, D.; Teuteberg, F. & 2018 & Customer segment \\
\hline
\end{tabular}

the objects of interest". The result of the aforementioned subjective ending conditions is a comprehensive and usable taxonomy, by which all known objects can be classified. Nevertheless, a useful taxonomy should be extendible and "allow for inclusion of additional dimensions and new characteristics within a dimension" (Nickerson et al. 2013).

The findings of our literature review were analysed to derive dimensions and characteristics for our initial taxonomy. The first taxonomy was developed with 8 dimensions and 24 characteristics by discarding some of the proposed dimensions because (a) information about certain dimensions of the respective business models is difficult to obtain or (b) the information is not suited for our taxonomy. In June 2018, we then searched for start-ups on chain.de, crunchbase.com, icobench. com, and angel.co/blockchains. The focus of our selection was on blockchain-based start-ups which already carried out or planned an ICO (Status "Ended" or "Ongoing") and provided sound information about their respective business model. The data analysis was based on various sources (including the company's website, whitepapers, social media channels, press reports). Since we attached great importance to consistent and comprehensive information, we deleted those companies from the list for which only incomplete or contradictory information was found. In total, we were able to identify 195 start-ups in this area and gather the relevant information.

For the development (empirical-to-conceptual approach) and the application of our taxonomy, we then analysed these start-ups. In order to avoid bias, we used www.random.org to select start-ups from our aforementioned representative list. Table 2 displays the start-ups that have led to enhancements in the taxonomy. In the first iteration, we analysed five startups from our list. The analyses of these real-life use cases expanded the taxonomy by two new dimensions: "market types" and "types of decentralized business models".

In order to achieve a high reliability of our analysis and classification of start-ups, we took stability and reproducibility into account (Krippendorf 2004). All perspectives, dimensions and characteristics as well as coding examples served as the basis for our codebook to classify start-ups, which in turn contributed to the stability of our analysis. In order to achieve a high degree in reproducibility, two experienced researchers worked independently on the analysis of the data and discussed existing contrasting opinions in a next step. We used Krippendorff's alpha to determine the inter-rateragreement, which is an indication of the convergence between the raters. The calculated value of 0.87 fits the "usual" target value of 0.8 (Krippendorf 2004).

The relevant markets can be differentiated according to the characteristic whether they are one-sided, two-sided or multisided. By means of the second new dimension, types of decentralized business models, the tokens within a tokenbased ecosystem can be divided into two main categories, depending on their level of decentralization. Since we created further dimensions and characteristics in this iteration, the objective ending condition "no new dimensions or characteristics were added in the last iteration" did not apply, which required a second iteration. In the second iteration, we analysed the next five use cases, which led to another new dimension: "Level of control". This dimension takes into account that the service provider within a collaborative platform is under the control of the platform.

Since the type of use of the tokens has a significant impact on the value of the ecosystem, in the dimension "token incentive", we additionally distinguish between the three 
Table 2 Overview of the analysed start-ups that led to enhancements in the taxonomy

\begin{tabular}{|c|c|c|c|}
\hline Start-up & Business Model in brief & Used documents and Homepage & Pub.Date \\
\hline BEAT & $\begin{array}{l}\text { The BEAT Blockchain will enable the user to } \\
\text { store his verified sports health and activity } \\
\text { data anonymously and encrypted in the } \\
\text { Blockchain. }\end{array}$ & $\begin{array}{l}\text { Onepager; ICO Whitepaper; Token Sale } \\
\text { Terms. https://beat.org }\end{array}$ & 08.2018 \\
\hline OCEAN & $\begin{array}{l}\text { Ocean Protocol is an ecosystem for sharing } \\
\text { data and associated services. Ocean helps } \\
\text { to unlock data, particularly for AI. }\end{array}$ & $\begin{array}{l}\text { Token Distribution Details; Reference } \\
\text { Marketplace Framework; Technical } \\
\text { Whitepaper. https://oceanprotocol.com }\end{array}$ & 08.2018 \\
\hline ConcertVR & $\begin{array}{l}\text { The first blockchain based cross-platform } \\
\text { marketplace for high-quality VR content } \\
\text { from the music and entertainment sector. }\end{array}$ & $\begin{array}{l}\text { Whitepaper Version 1.7. https://www. } \\
\text { concertvr.io }\end{array}$ & 10.2018 \\
\hline Hydrocoin & $\begin{array}{l}\text { HydroCoin (HYC) is the first cryptocurrency } \\
\text { for the blockchain community empowering } \\
\text { hydrogen industry }\end{array}$ & Whitepaper 2018. https://hydrocoin.org & 10.2018 \\
\hline CloudEO & $\begin{array}{l}\text { CloudEO is an ecosystem of geodata } \\
\text { providers offering affordable geoservices to } \\
\text { individuals, businesses, industry, and the } \\
\text { public sector. }\end{array}$ & $\begin{array}{l}\text { Ceven-foundation-whitepaper 2018-08-23. } \\
\text { https://cbn.foundation }\end{array}$ & 08.2018 \\
\hline Edgecoin & $\begin{array}{l}\text { Edgecoin is the world's first education and } \\
\text { e-learning token built on the Ethereum } \\
\text { blockchain. }\end{array}$ & $\begin{array}{l}\text { Edgecoin Whitepaper v1.0 March 19th } 2018 . \\
\text { https://www.edgecoin.io }\end{array}$ & 03.2018 \\
\hline Copytrack & $\begin{array}{l}\text { COPYTRACK is designed to help } \\
\text { photographers comfortably settle image } \\
\text { theft on the Internet. }\end{array}$ & $\begin{array}{l}\text { Global Copyright Register: Technical Paper. } \\
\text { http://www.copytrack.com }\end{array}$ & 10.2018 \\
\hline GamingStars & $\begin{array}{l}\text { Gaming Stars is an ongoing decentralized } \\
\text { platform built on top of Ethereum that aims } \\
\text { to revolutionize the global eSports industry. }\end{array}$ & $\begin{array}{l}\text { Whitepaper Version 0.9, Last update: } \\
\text { Sept 19th 2018. https://gaming-stars.net }\end{array}$ & 09.2018 \\
\hline Esports & $\begin{array}{l}\text { Esports aims to create the biggest eSports } \\
\text { portal in the world. }\end{array}$ & Whitepaper. https://www.esports.com/ & 10.2018 \\
\hline LenusChain & $\begin{array}{l}\text { LenusChain will offer users the possibility of } \\
\text { creating health spaces in which data of } \\
\text { different wearable manufactures can be } \\
\text { combined, evaluated and monitored. }\end{array}$ & $\begin{array}{l}\text { Executive Summary, Whitepaper. } \\
\text { https://lenuschain.io }\end{array}$ & 10.2018 \\
\hline IamHero & $\begin{array}{l}\text { Iamhero focusses on creating solutions, which } \\
\text { help all people in their individual lives, by } \\
\text { which anybody can create an online resume } \\
\text { at the IAMHERO (IAH) platform. }\end{array}$ & ICO Whitepaper. https://iamhero.io/ & 10.2018 \\
\hline Herdius & $\begin{array}{l}\text { Herdius intends to build a highly performant } \\
\text { decentralized financial platform. }\end{array}$ & $\begin{array}{l}\text { Tokenomics, Whitepaper 1.1. https://herdius. } \\
\text { com }\end{array}$ & 10.2018 \\
\hline Helix & $\begin{array}{l}\text { HELIX Orange establishes a compliant and } \\
\text { sustainable ecosystem for international } \\
\text { investors and global Initial Coin Offerings } \\
\text { ("ICO projects" or "ICOs"). }\end{array}$ & $\begin{array}{l}\text { Onepager v1.5, Whitepaper v1.5. https://ico. } \\
\text { helix-orange.com }\end{array}$ & 07.2018 \\
\hline Staramba & $\begin{array}{l}\text { Our VR world STARAMBA.spaces make } \\
\text { possible to meet celebrities in person. The } \\
\text { MyStarCities of the users will be } \\
\text { securitized by a blockchain. }\end{array}$ & $\begin{array}{l}\text { Whitepaper, Version } 1.0 \text { - 23rd May, } 2018 . \\
\text { https://www.staramba.com }\end{array}$ & 05.2018 \\
\hline
\end{tabular}

characteristics active work, passive work and no work. Given the fact that the taxonomy had to be extended also in the second iteration, that is the ending condition did not yet apply, we analysed the next use cases in a third iteration. As the analyses of the remaining startups did not reveal further dimensions and characteristics, all ending conditions were fulfilled.

Concerning our defined meta-characteristics, the taxonomy covers all relevant aspects for a token-based ecosystem. The defined perspectives relating from our definition have more than one dimension with more than one characteristic each.
In order to understand token-based ecosystems, we used cluster analysis to identify typical patterns, the so called archetypes (Eickhoff et al. 2017). The use of cluster analysis has strongly increased in recent periods (Kettenring 2006). Rossignol et al. (2018) mentioned that clustering is "probably the most common and intuitive tool used both by human cognition and artificial data analysis in an attempt to make that data organized, understandable, manageable". Lerman (2016) described clustering as a central tool in data analysis, while Masulli and Rovetta (2012) added that "clustering aims to find a structure that aggregates the data into some groups with the 
property that data belonging to a group (or cluster) are more similar to data in that cluster than to data in other clusters."

We were able to determine the relevant data from whitepapers, the homepages of the start-ups and from the internet databases icobench.com and crunchbase.com. The characteristics in our taxonomy were dichotomized with 1 if the characteristic is observable and 0 if not.

Before we performed the cluster analysis, we investigated the Pearson correlation between our characteristics. The highest correlations are between cooperative performance and two-sided markets with 0,160 and between price and one-sided markets with 0.165 . Both results are on a very low level, therefore, we can proceed with the cluster analysis.

All analyses were carried out in SPSS (version 24). For cluster analysis, we used the "Wards's Method", the most commonly used variance method. By means of this method, the clusters that generate the least increase in variance in the new cluster are merged. This corresponds to a minimal increase in the error square sum by the fusion of two clusters. The increase in heterogeneity should thus be minimized by merging two clusters (Lerman 2016). The algorithm is hierarchical because the number of subsets is systematically reduced based on the premise that "the greatest amount of information as indicated by an objective function is available when a set of n members is ungrouped" (Ward 1963).

The similarity between two start-up companies is measured by the number of identical characteristics in the respective dimensions. Squared Euclidean distance was chosen as distance measure, which can be used for binary variables. With the help of the dendrogram, the distance coefficients ${ }^{1}$ and the screen test, the number of clusters could finally be determined. The aggregation scheme of the cluster method according to the Ward's method represents the increase in heterogeneity in each step and with the respective number of clusters. The higher this value is, the greater the difference between the start-ups in the clusters. It can be seen that the heterogeneity increases disproportionately in step 11 to step 12 (coefficient increases by 59.4\%) and in step 17 to 18 (coefficient increases by $21.3 \%$ ). Therefore, reducing the number of clusters from seven to six or from three to two would result in a disproportionate increase in heterogeneity.

Since the increase in heterogeneity of the Ward's method is to be minimized by the merging of two clusters, the aggregation scheme of the cluster method indicates that a three- or a seven-cluster solution is most suitable. The disproportionate increase in heterogeneity in a seven-cluster and three-cluster solution is also represented in the screen test using the Elbow criterion. Thus, the screen test also indicates a three- or a seven-cluster solution.

In the next step, the possible cluster solutions (three and seven clusters) were compared using the K-Means method.

\footnotetext{
$\overline{1}$ (increase in heterogeneity or decrease in homogeneity)
}

The K-Means method is an iterative cluster method in which a predetermined number of $\mathrm{k}$ clusters is formed from a number of objects in several passes so that the sum of the squared deviations from the cluster focal points is minimal (Finch 2005). The goal of this cluster analysis is to achieve the greatest possible homogeneity within the clusters while maximizing the heterogeneity between the clusters. Subsequently, both solutions (three and seven clusters) were evaluated with regard to content and logical aspects between the researchers. A three cluster solution was considered more useful, as the differences between the companies were quite sharp in the clusters. With the seven-cluster solution, the clusters were not clearly defined and are therefore not suited to highlight the differences between the business models clearly.

\section{Taxonomy}

Our taxonomy of token-based ecosystems for blockchain based start-ups, that is based on a sound literature analysis (cf. Table 1) as well as the findings of the analyses of the start-ups, is depicted in Table 1. The first column represents the perspectives related to the keywords used to describe our view of an ecosystem. Each dimension of the taxonomy is assigned to one of the aforementioned perspectives. Further, we distinguished between exclusive and non-exclusive dimensions. An example of a non-exclusive dimension is the dimension customer segment, in which a platform can have both business customers (B2B) and individual customers (B2C). Table 3 also shows in which iteration of the empirical-to-conceptual approach the dimensions were added or revised. The dimensions and characteristics of our taxonomy are described in the following.

To exemplify our taxonomy on a specific example, the number in brackets in the previous Table 3 shows the characteristics of the start-up Crycash.io. The following explanations in brackets again refer to the brackets in the taxonomy. CRYCASH is a cryptocurrency that satisfies all needs of gamers and game developers with its Ecosystem services (B2B + B2C). It is an independent decentralized ecosystem build on Ethereum. (some dependences on trusted 3rd parties). Game developers will benefit from using the Platform by reducing customer acquisition costs (Associate $=$ Partner). Beside game developers also gamers and the gaming industry are winning profit (multisided). The birth of crycash is at the beginning of 2017 (expansion). CRYCASH build an ecosystem consisting of Plink application, Advertising Platform, Decentralized Marketplace for trading games and in-game items, Cybersport Platform (contract term). Game developers use tokens to promote their products and attract gamers (C. Incentive Schemes). The crycash tokensale started at the end of 2017 (Initial Coin Offerings). CRYCASH Software Development Kit (SDK) is designed for developers to create their in-game marketplace to sell in-game items and earn 


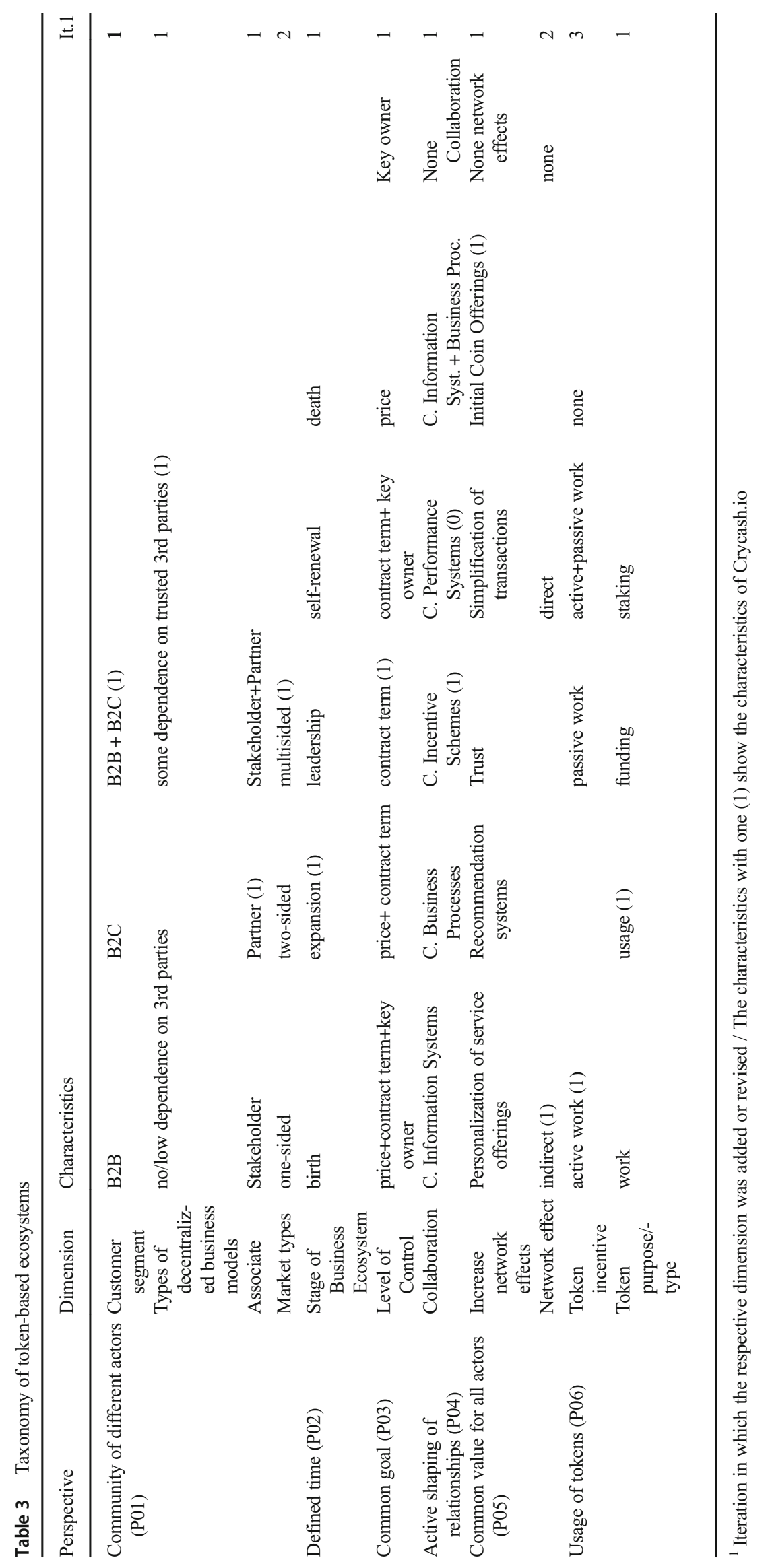


CRYCASH (active work). CRYCASH operates with its own utility token called "CRC" (usage token). This example leads to an expansion model (see Table 5).

\section{Community of different actors, [P01]}

- Customer segment: We identified two major customer segments. The business-to-business relationships (B2B) and the business-to-consumer relationships (B2C) (Morris et al. 2005).

- Types of decentralized business models: Depending on their level of decentralization, the tokens within tokenbased ecosystems can be grouped in two main categories. The first is the decentralized business model with no or low dependence on trusted third parties. The main criterion here is whether the tokens are a native part of an open sourced blockchain and therefore not dependent on third parties. The other category is a decentralized business model with a certain dependence on trusted third parties. Within this business model, Bitcoin or Ethereum technology is used. The owner of the tokens therefore needs trusts in the platform as well as in third parties (McKie 2017).

- Associates: The actors in our token-based ecosystems can be differentiated into stakeholders and partners. Both have a strong relationship to the ecosystem, but the main difference is that the stakeholder is defined only by token ownership, in contrast to partners who take an active part in the respective ecosystem (McKie 2017).

- Market types: A distinction can be made between onesided, two-sided and multi-sided markets and platforms. In a one-sided market or platform, the consumer buys the product from a retailer and has no relationship to the producer of the product. Therefore, the platform or market has only one side. Two-sided platforms or markets have distinct customer groups that are brought together by an intermediary platform in order to generate value. Thereby, each customer group represents one side in this market (Theurl and Meyer 2019). Multi-sided platforms support two or more different groups to find each other and interact (Evans and Schmalensee 2016) and "...typically comprise a stable core, a dynamic set of complementary assets and the design rules acting as interfaces between them" (Mattila and Seppälä 2018).

\section{Defined time, [P02]}

- Stages of the Ecosystem: The lifecycle of an ecosystem consists of four different stages. The cooperation of business partners, who jointly define the customer value proposition, constitutes the first stage, i.e. the birth of an ecosystem. An essential part within the first stage is to win important business partners for the ecosystem. Another significant challenge is that customers and suppliers work together in order to define the value proposition for each participant. In the next phase, the ecosystem will be expanded by opening further possible business territories. This development thus represents competition with other ecosystems and is aimed at achieving market leadership. At the end of the lifecycle, there is a mature ecosystem, which will, however, be constantly threatened by new innovations and other ecosystems that occur due to amended governmental regulations, changing customer buying patterns or macroeconomic conditions (Moore 1993).

\section{Following a common goal, [P03]}

- Level of control: The providers of services within a collaborative platform are under the control of the platform. The level of control over providers and their services is generally important for the collaboration and the common value of the ecosystem (European Commission 2016). Moreover, the level of control can be divided into three major aspects. One important aspect of control is the price setting within the ecosystem. Does the collaborative platform set the final price that the user has to pay, or is it only a recommendation? Another equally important aspect in ecosystems is the determination of contractual terms between producer and consumer. Besides, a distinction has to be made between who determines the contractual conditions, the platform or the respective partners involved. The underlying service of a collaborative platform uses assets as part of the total added value. Here the decisive question arises of who is the owner of these assets (European Commission 2016).

\section{Active shaping of relationships, [P04]}

- Collaboration: Collaboration is a central aspect in an ecosystem and the basis of value creation for all participants. So far the idea of collaboration has been limited to the same or a similar sector, but with digital ecosystems new patterns of competition and cooperation are emerging (Park 2018). We adopt Simatupang's (2007) research for supply chain collaboration and differentiate between four types of collaboration. First there are collaborative information systems with the key research question "Which information drives the optimization of total profits?". Information is the most relevant factor for successful collaboration. The second are collaborative business processes where the process constitutes the driving factor for matching producer and consumer. The key research question here is "Which processes generate the highest overall 
profits?". The next crucial question "Which incentive mechanisms drive productive behavior?" leads us to collaborative incentive schemes. Above all, the performance of ecosystems depends on the behavior of the participants and therefore also on the incentives for the actors to become actively involved or not. (Simatupang 2007). Last but not least, the collaborative performance system and the research question "Which performance measurement drives total improvements?" are the basis for the mutual success of the ecosystem.

\section{Reaching a common value for all actors, [P05)}

- Increase network effects: A platform is successful if it generates value to its users. In two-sided and multi-sided markets, this value depends on the amount of offerings for the respective market sides. This impact is described as the network effect (Parker et al. 2016). A strategy to increase network effects is the personalization of services offered on the platform (e.g. google, amazon). Another strategy is to induce satisfied platform customers to make respective recommendations. But also trust mechanisms are effective methods that help to dispel customers' skepticism about the use of the platform (Salminen et al. 2018). In particular, the creation of an easy-to-use and understandable platform can attract new customers and increase network effects (Subramanian 2018).

- Network effect: There are two different types of network effects, the direct and the indirect. The direct network effect describes the situation where a new participant on the platform brings a direct positive value to all other participants. The other way to create added value for the already involved platform parties is the addition of a completely new type of participant to the platform (Evans and Schmalensee 2016).

\section{The usage of tokens as a value of the ecosystem, (P06)}

- Token incentive: Users of an ecosystem can obtain the necessary tokens to participate in that ecosystem by changing fiat or cryptocurrencies to the respective tokens, or by contributing to the value of the ecosystem, for which they are then rewarded with tokens. Two types of contributions can be distinguished: The first is the active work for the platform economy, for example recommending the platform to new customers, the second is the sharing or disclosing of own data (Mougayar 2017).

- Token purpose/type: Depending on the purpose of tokens, they have a significant impact on the success of a platform ecosystem. On the one side, there are usage tokens that allow owners to use a service offered by the platform (also named as a utility token). Thus, if a user wants to participate in the development of or work on the platform, he needs the usage tokens. The funding tokens, on the other side, are only relevant for fund raising, and the staking tokens finally enable platform participants to acquire rights as stakeholders (Fridgen et al. 2018).

\section{Application of the taxonomy}

\section{Archetypes of token-based ecosystems}

Based on our definition of token-based ecosystems with the relevant perspectives and the developed taxonomy with the related dimensions and characteristics, we reinvestigated randomly drawn data points from the 195 start-ups from our list and discussed in the research team whether a reassessment of certain dimensions is necessary. The derivation of the archetypes was supported by an experienced researcher in this field.

To validate the aforementioned three cluster solution, we used the frequencies in the descriptive statistics.

Table 4 shows 195 objects within the cluster analysis and 72 objects for cluster 1 with a relative cluster size of $36.9 \%$. Cluster 2 has 75 objects and a relative cluster size of $38.5 \%$ and cluster 3 has 48 objects with a size of $24.6 \%$. In order to determine the focus of our clustering variables, we use the cluster as a grouping variable to compare the groups and to present the mean for all characteristics for every cluster.

As a result of our cluster analysis, we yielded three archetypes that can be connected to the commonly used framework for the stages of organization by Moore (1996): (1 Pioneering (Vision) model) platform-based old economy with some dependence on trusted third parties, (2 - Expansion model) platform-based ecosystem with some dependence on trusted third parties, and (3-Authority model) platform-based ecosystem with an own blockchain (cf. Table 5). The archetype Pioneering (Vision) model is characterized by the fact that the associates of the business are almost exclusively described as partners (86.7\%), a business relationship that is not based on the token as value. This leads to little (or no) collaboration $(54.7 \%)$ between the business partners. Hence, this business model comes without the support for the network effect in $89.3 \%$ of the cases, without the need to promote the

Table 4 Frequencies of the clusters

\begin{tabular}{lccc}
\hline Cluster & Frequency & Percent & Cumulative percent \\
\hline 1 & 72 & 36.9 & 36.9 \\
2 & 75 & 38.5 & 75.4 \\
3 & 48 & 24.6 & 100.00 \\
Total & 195 & 100.0 & \\
\hline
\end{tabular}




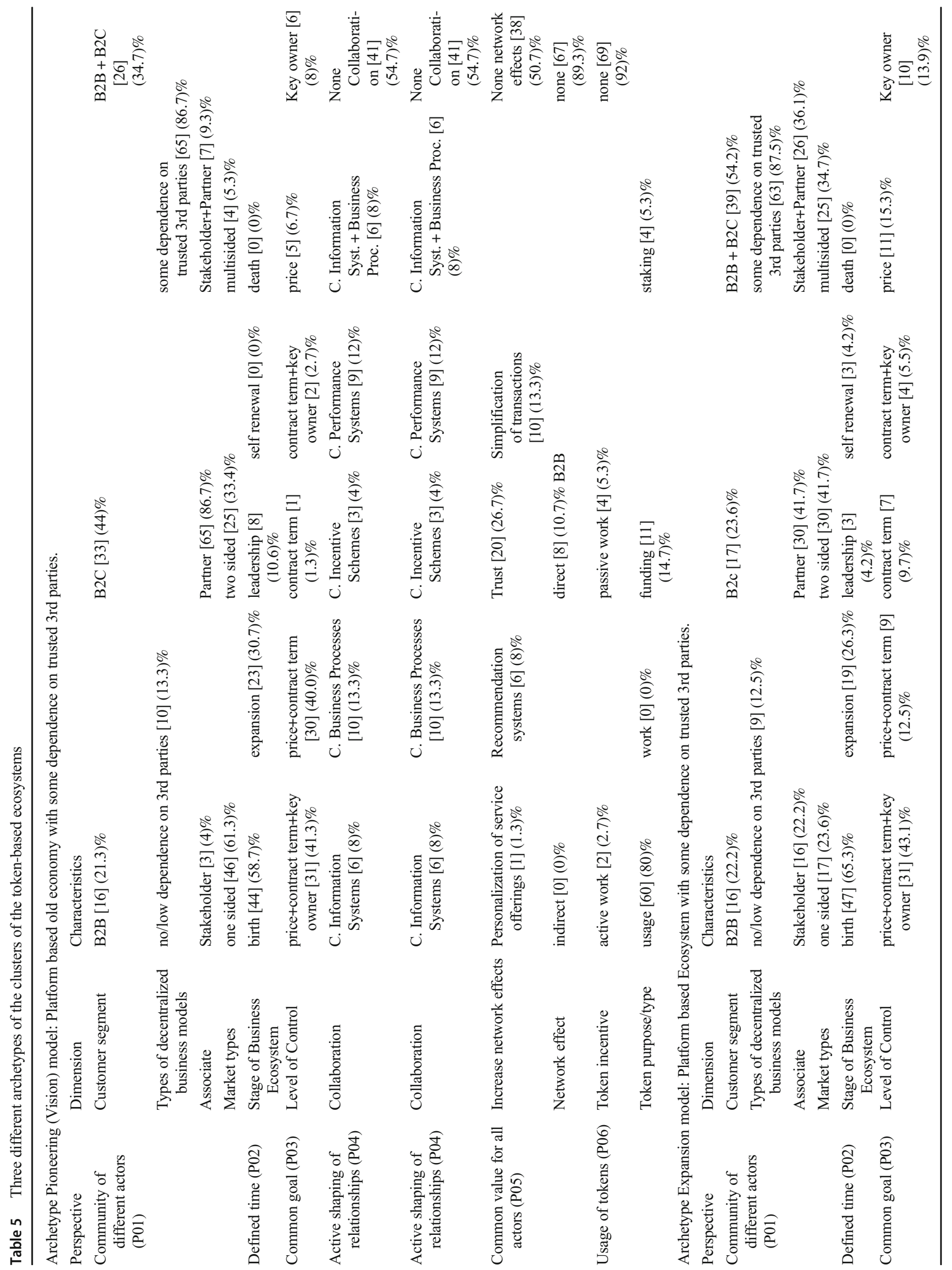




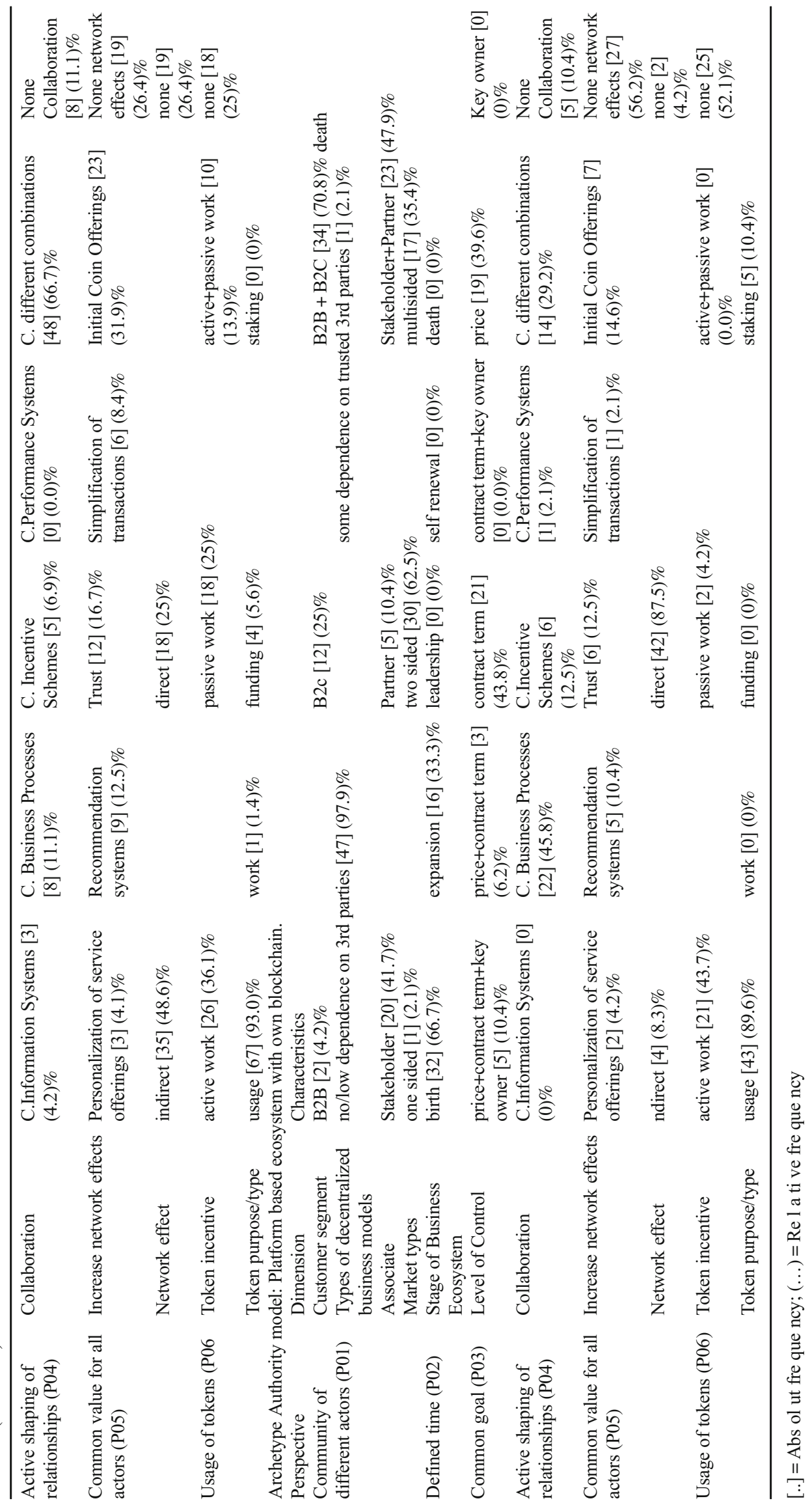


token $(92 \%)$ and is predominantly based on a one-sided market $(61.3 \%)$ with indirect customers (B2C) $(44.0 \%)$. A high level of control therefore makes sense, mainly determined by price and contract terms (40\%). The archetype Expansion model has various different relationships with stakeholders (22.2\%) and partners $(41.7 \%)$, so the collaboration is mainly based on a mix of collaborative tools $(66,7 \%)$. The success of the collaboration in an ecosystem requires a change in attitudes from protectionist to co-operative (Peltoniemi 2005). Stakeholders are part of the token-based ecosystem and therefore the indirect network effect (48.6\%) as well as the combination of active work $(36.1 \%)$ and passive work $(25.0 \%)$ increase the network effect, resulting in added value for the stakeholders. These businesses are mostly focused on twosided $(41.7 \%)$ and multi-sided markets $(34.7 \%)$. The high amount of stakeholders and B2B segments leads to high values in collaborative business processes (11.1\%) and collaborative incentive schemes (6.9\%). Our third archetype Authority model shows stakeholders in business relationships (41.7\%). In addition, it is noticeable that in many cases this archetype is used to target direct network effects (87.5\%). The level of control in this ecosystem is significantly lower compared to the other archetypes (price $39.6 \%$, contract terms $43.8 \%)$. The market types are mostly two-sided $(62.5 \%)$ or multi-sided (35.4\%). It can thus be concluded that the level of control is lower in order to increase the variety of possible business models based on the ecosystem and therefore attract new business partners. To achieve this, these business models have little or no dependence on third parties (97.9\%).

The role of the token as the main element of a token-based ecosystem is different in the three archetypes. In the archetype Pioneering (Vision) model, the token is mainly used in exchange for benefits, with no special activity to increase the token value. For this reason, network effects play only a minor role. Further, the provider usually determines prices and contract terms. The archetype Pioneering (Vision) model can thus be recommended for start-ups that intend to finance themselves through the ICO and that use the tokens solely as a means of payment for customer-related services.

In the archetype Expansion model, the active involvement of stakeholders is paramount in order to increase the value of the tokens for all involved stakeholders. Therefore, the network effect plays a significant role here. Furthermore, the degree to which prices and contract terms are set by the provider is significantly lower. This makes the archetype Expansion model suitable for start-ups that intend to finance themselves through an ICO and implement a business model with partners and a common currency.

Compared to the other archetypes, the Authority model shows the lowest level of control. As neither price nor contract terms are subject to significant specifications of the provider, direct network effects play a major role. The inclusion of new partners in the business model brings a direct positive contribution for all participants. With the archetype Authority model innovative and value-oriented business models can be built with business partners by using an own blockchain and enabling network effects, in order to be successful in the $\mathrm{B} 2 \mathrm{C}$ segment.

\section{Discussion and implications}

The application of our taxonomy of token-based ecosystems to 195 start-ups resulted in the identification of three archetypes, which again serve the empirical validation of our taxonomy: the Pioneering (Vision) model, the Expansion model and the Authority model. These archetypes follow Moore's life-cycle of a business ecosystem (1996). The first phase Pioneering (Vision) is characterized by the creation of a viable and "exciting" alternative to the status in the industry, while the development of an ongoing operation and strong relationship to customers and suppliers is the focus of the second phase Expansion. The third phase Authority is characterized by the goal to gain the authority within the ecosystem (Moore 1996).

The Pioneering (Vision) model can be characterized as the first cautious approach of a token-based ecosystem. Although the initial coin offerings provide tokens as new currency in the business model, the start-ups within the Pioneering (Vision) model do not take full advantage of the new opportunities, rather they continue to operate a business with high control via price, contract terms, and assets. This is also reflected in the market type with focus on one-sided markets and low levels of collaboration activities. Although the start-ups implement tokens for billing purposes with their customers, they do not take advantage of the opportunities to increase network effects or promote the use of the tokens. Thus, the tokens are used exclusively for payment processes.

The start-ups in the archetype Expansion model, use the tokens in order to develop a token-based ecosystem with stakeholders, implement mechanisms to increase the indirect and direct network effect and create an added value for all participants. The level of control in these start-ups is significantly lower and they allow their business partners to create own revenue models on the basis of the token-based ecosystem. Furthermore, the active shaping of relationships to business partners plays an important part and shows different ways of cooperation, mainly by collaborative information systems and collaborative business processes.

Start-ups in the archetype Authority model show a similar business model to start-ups in the Expansion model, but there is less dependence on third parties and a lower level of control through pricing, contract terms, and assets. As the majority of the business partners are stakeholders and the start-ups have their own blockchain system with their own native token, the network effect plays an important role in increasing the value of the tokens for all participants in this ecosystem. The direct 
network effect combined with the simplification of transactions and trust leads to a common value.

The chicken-and-egg problem applies to both the Expansion model and the Authority model, because the share is relatively high in multi-sided markets. This problem describes the dilemma that a critical number of sellers or vendors is necessary to be of interest to customers as a platform. However, the sellers or vendors can only be acquired to participate in a platform if they have a sufficient number of customers (Stummer et al. 2018). For token-based ecosystems, this dilemma can be tackled by issuing airdrops, in which free tokens are distributed for certain services such as recommendations. The distribution of tokens for free follows the goal of increasing popularity and to build a strong base of active users early on. A broad distribution of the tokens over various users has proven to be helpful. The major goal is to raise awareness (Malwa 2018). For example, each owner of the cryptocurrency Ether could receive one free token per Ether without actively taking action for it. On the one hand airdrops constitute a well-functioning marketing tool, on the other hand they create an important first customer base to attract suppliers to the platform (Brennecke et al. 2018). The archetypes Expansion model and Authority model logically show high values for the necessary measures in token incentives.

\section{Implications for research}

The first implication of this paper is its contribution to understanding the different aspects of token-based ecosystems. The tokens created by start-ups and sold via initial coin offerings can be the basis for new ecosystems, based on the blockchain. However, we have seen that some start-ups use tokens as a link between consumers, producers, and platform providers, while others only use them as a fundraising tool. The challenge for those who use tokens as an integrative part of their business models is to increase the value of the tokens. We have seen that business models are different when it comes to promoting the network effect in order to create a solid basis for consumers and producers. Although the chicken-and-egg problem can be addressed by means of some token incentives, $48.1 \%$ of the start-ups do not take advantage of this possibility. Our taxonomy therefore provides a sound basis for future research on network effects for token-based ecosystems. In our taxonomy, we used the characteristics active work, and passive work to stimulate the tokens. Future research could explore these two aspects in more detail to identify further characteristics for token incentives and their impact on business models. Another important aspect for future research lies in the symbioses between the collaboration within the stakeholders of an ecosystem and the value of the associated tokens. What influence does the depreciation of a token have on the collaboration of the token-based ecosystem? Many startups seem to be influenced by the success of some ICOs and try to follow the same crowdfunding approach. It is still unclear what exactly makes start-ups successful that use ICO as crowdfunding method. Future research should therefore also focus on the possible success factors for token-based ecosystems based on the blockchain. Finally, by further exploring token-based ecosystems, our taxonomy could be extended by new dimensions and characteristics.

To the best of our knowledge, this is the first Taxonomy of token-based ecosystems of blockchain-based business models of 195 start-ups. The taxonomy helps to structure and understand the vast amount of token-based ecosystems of blockchain-based business models. And this on the basis of real use-cases. Second, the taxonomy further serves as a blueprint for new start-ups to design your business models in the context of blockchain-based ecosystems. Third, the taxonomy addresses several aspects for future research, like the chickenegg problem for network based business models or the dilemma of two-sided markets and the issuance of airdrops as a solution.

\section{Implications for practice}

Equally for practitioners our research provides some useful insights. First, our taxonomy can be used to analyse competitors. In this way, possible economic niches can be identified, which then might offer interesting perspectives for future start-ups. Second, managers should start thinking about the potential impact of blockchain technology on their business model. Although the taxonomy cannot be used as a blueprint, it can be used as a tool to boost creativity, e.g. in workshops on the (further) development of business models (Remane et al. 2016). For instance, existing pipeline-business models might be converted (or supplemented) to a token based ecosystem. Therefore, our archetypes of token-based ecosystems can be used as a conceptual basis for strategic considerations for businesses. Thirdly, the taxonomy and the derived archetypes can be used to reveal the fundamental differences between the identified token-based ecosystems, as our contribution analyses 195 different ecosystems and not just a few as in previous papers. Although our taxonomy and archetypes represent the status quo, we do not claim our research to be complete. Nevertheless, our work can be used as a starting point by entrepreneurs, as it can be adapted and/or extended depending on the specific business model.

In addition, our work can support governments and regulators in adapting regulatory frameworks through a better understanding of token-based ecosystems. Various examples in the past show that new technologies such as cloud computing are often associated with complex regulatory challenges (e.g. regarding privacy). 


\section{Conclusion, limitation, and outlook}

The aim of this paper was to investigate platform-based business models of start-ups using a token-based ecosystem. In the context of this research relevant dimensions and characteristics of blockchain-based ecosystems were analysed and visualised in a taxonomy. Furthermore, based on the taxonomy, three generic archetypes were derived. Both the taxonomy and the archetypes allow scientists, practitioners, and governmental actors a better understanding of token-based ecosystems. For instance, economic niches can be identified from a practical point of view.

Nevertheless, as with any research, limitations need to be mentioned. First, our sample of ICO start-ups is not exhaustive. According to www.icobench.com in October 2018, there are over 4.500 ICOs. However, we have deliberately chosen to focus on the most recent start-ups in order to keep track of the current state in this field. We believe that the high dynamics in recent years within these business models as well as the underlying technology would otherwise lead to inadequate comparisons. This means that an ICO start-up from 2014 should not be compared with a current ICO start-up. Second, our analyses are mostly based on information provided by third parties like ICObench.com, crunchbase.com or chain.de. For a validation, however, we have reviewed and compared the information on the homepages and whitepapers of the start-ups. Third, our collection of relevant perspectives, dimensions, and characteristics is dependent on the results of our literature research, our previous experience of analysing business models, and the examination of the identified start-ups. Our work can serve as a starting point for further research activities. Thus, interesting and promising opportunities arise in (a) the analysis of other companies, (b) the analysis of the same companies at a later stage to identify possible changes and (c) the evolution of the taxonomy by adding further dimensions. Furthermore, the different legal frameworks in the respective countries could be examined, similarities and differences could be identified and their effects on the ecosystem analysed.

Acknowledgements The authors would like to thank Ms. Imhorst and Mr. Schulte to Brinke, for their valuable and substantive help, as well as the reviewers for their constructive feedback.

Funding Information Open Access funding provided by Projekt DEAL.

Open Access This article is licensed under a Creative Commons Attribution 4.0 International License, which permits use, sharing, adaptation, distribution and reproduction in any medium or format, as long as you give appropriate credit to the original author(s) and the source, provide a link to the Creative Commons licence, and indicate if changes were made. The images or other third party material in this article are included in the article's Creative Commons licence, unless indicated otherwise in a credit line to the material. If material is not included in the article's Creative Commons licence and your intended use is not permitted by statutory regulation or exceeds the permitted use, you will need to obtain permission directly from the copyright holder. To view a copy of this licence, visit http://creativecommons.org/licenses/by/4.0/.

\section{References}

Adner, R. (2017). Ecosystem as structure: An actionable construct for strategy. Journal of Management, 43(1), 39-58.

Agrawal, A., Catalini, C., \& Goldfarb, A. (2014). Some simple economics of crowdfunding. Innovation Policy and the Economy, 14(1), 63-97.

Ahlers, G. K. C., Cumming, D., Günther, C., \& Schweizer, D. (2015). Signaling in equity crowdfunding. Entrepreneurship Theory and Practice, 39(4), 955-980.

Basole, R. C. (2009). Structural analysis and visualization of ecosystems: a study of mobile device platforms. AMCIS 2009 Proceedings. 292.

Beinke, J. H., Nguyen, D., Teuteberg, F. (2018). Towards a business model taxonomy of startups in the finance sector using Blockchain. Proceedings of the 39th International Conference on Information Systems (ICIS), San Francisco, USA.

Bitcoinexchangeguide (2018). ICO Value: What drives the price of initial coin offering tokens? https://bitcoinexchangeguide.com/ico-value/. Accessed 11/14/2018.

Brandon, D. (2016). The Blockchain. The future of business information systems? International Journal of the Academic Business World Fall, 10(2), 33-40.

Brennecke, M., Fridgen, G., Guggenberger, T., Radszuwill, S. (2018). Blockchain and initial coin offerings: Blockchain's Implications for Crowdfunding, in: Business transformation thorug Blockchain, Treiblmaier, H./ Beck, R. (Hrsg.), Springer Interna-tional Publishing (2019), https://doi.org/10.1007/978-3-319-98911-2.

Bruton, G., Khavul, S., Siegel, D., \& Wright, M. (2015). New financial alternatives in seeding entrepreneurship: Microfinance, crowdfunding, and peer-to-peer innovations. Entrepreneurship Theory and Practice, 39(1), 9-26.

Chanson, M., Gjoen, J., Risius, M., \& Wortmann, F. (2018). Initial coin offerings (ICOs): The role of social Media for Organizational Legitimacy and Underpricing. In proceedings of the 39th international conference on information systems (ICIS). San Francisco, CA.

Chapin, F. S., Matson, P. A., \& Vitousek, P. M. (2011). The ecosystem concept. In Principles of Terrestrial Ecosystem Ecology. New York, NY: Springer. https://doi.org/10.1007/978-1-4419-9504-9 .

Chen, Y. (2018). Blockchain tokens and the potential democratization of entrepreneurship and innovation. Business horizons, Stevens Institute of Technology School of Business Research Paper., 61(4), $567-575$.

Choudary, S. P. (2015). Platform scale. In How an emerging business model helps startups build large empires with minimum investment? $I^{\text {st }}$ edition. Platform Thinking: Labs. Pte. Ltd..

Conley, J. P. (2017). Blockchain and the Economics of Crypto-tokens and Initial Coin Offerings, Vanderbilt University Department of economics working papers, VUECON-17-00008.

Dhillon, V., Metcalf, D., Hooper, M. (2017). Blockchain enabled applications. Understand the Blockchain Ecosystem and How to Make it Work for You. Apress, https://doi.org/10.1007/978-1-4842-3081-7 .

Ehrsam, F. (2016). Blockchain tokens and the dawn of the decentralized business model. https://blog.coinbase.com/app-coins-and-thedawn-of-the-decentralized-business-model-8b8c951e734f. Accessed 09/26/2018.

Eickhoff, M., Muntermann, J., \& Weinrich, T. (2017). What do FinTechs actually do? A taxonomy of FinTech business models? In 
proceedings of the international conference on information systems (ICIS). South Korea: Seoul.

Ethereum (2018). Create your own crypto-currency with Ethereum. https://ethereum.org/token. Accessed 08/19/2018.

European Commission (2016). A European agenda for the collaborative economy. Communication from the commission to the European Parliament, the council, the European economic and social committee and the committee of the regions. COM(2016) 356 final. https:// eur-lex.europa.eu/legal-content/EN/TXT/?uri=COM\%3A2016\% 3A356\%3AFIN. Accessed 01/13/2019.

Evans, D. S., \& Schmalensee, R. (2016). Matchmakers: The new economics of platform businesses: How one of the oldest business models on earth powers the most incredible companies in the world. Boston Massachusetts: Harvard Business Press Review.

EYGM Limited (2018). EY research: initial coin offerings (ICOs). https:// www.ey.com/Publication/vwLUAssets/ey-research-initial-coinofferings-icos/\$File/ey-research-initial-coin-offerings-icos.pdf. Accessed 12/11/2018.

Finch, H. (2005). Comparison of distance measures in cluster analysis with dichotomous data. Journal of Data Science, 3(1), 85-100.

Fridgen, G., Regner, F., Schweizer, A., Urbach, N. (2018). Don't slip on the initial coin offering (ICO) - A taxonomy for a blockchainenabled form of crowdfunding. European Conference on Information Systems (ECIS) 26, 2018, Portsmouth.

Glaser, F. (2017). Pervasive Decentralisation of Digital Infrastructures: A Framework for Blockchain enabled System and Use Case Analysis. Proceedings of the 50th Hawaii International Conference on System Sciences (HICSS 2017); Waikoloa Village, Hawaii, USA.

Glass, R. L., \& Vessey, I. (1995). Contemporary application-domain taxonomies. IEEE Software, 12(4), 63-76.

Gregor, S. (2006). The nature of theory in information systems. MIS Quarterly, 30(3), 611-642. https://doi.org/10.2307/25148742 .

Han, X., Martinez, V., Neely, A. (2018). Service in the platform context: A review of the state of the art and future research. In Smedlund, A., Lindblom, A., Mitronen, L. (Ed.). Collaborative Value Co-creation in the Platform Economy. Translational Systems Sciences. Volume 11. Springer Nature Singapore Pte Ltd. 2018.

Harris, A. (2017). What is an ecosystem made up of? https://sciencing. com/ecosystem-made-up-of-6574.html. Accessed 09/18/2018.

Hein, A., Böhm, M., \& Krcmar, H. (2018). Platform configurations within information systems research: A literature review on the example of IoT platforms. Multikonferenz Wirtschaftsinformatik, Lüneburg, Germany, 465-476.

ICODATA (2018). Funds raised in 2018. https://www.icodata.io/stats/ 2018. Accessed 09/26/2018.

Jacobides, M. G., Cennamo, C., \& Gawer, A. (2018). Towards a theory of ecosystems. Strategic Management Journal, 39, 2255-2276. https:// doi.org/10.1002/smj.2904

Kar, S., Chakravorty, B., Sinha, S., \& Gupta, M. P. (2018). Analysis of stakeholders within IoT ecosystem. In A. Kar, S. Sinha, \& M. Gupta (Eds.), Digital India. Advances in theory and practice of emerging markets. Springer, Cham. https://doi.org/10.1007/978-3-31978378-9 15

Kettenring, J. R. (2006). The practice of cluster analysis. Journal of Classification, 23, 3-30. https://doi.org/10.1007/s00357-006-00026 .

Krcmar, H., \& Hein, A. (2018). TP2.4: Business models of platform providers. http://tum-1lcm.de/en/project/ap2/tp24/. Accessed 09/19/ 2018

Krippendorf, K. (2004). Content Analysis. An Introduction to its Methodology. $2^{\text {nd }}$ edition. Sage publications Inc.

Lamarre, E., \& May, B. (2017). Winning in digital ecosystems. Digital/ McKinsey: Insights. January 2018. https://www.mckinsey.com/ business-functions/digital-mckinsey/our-insights/digital-mckinseyinsights/digital-mckinsey-insights-number-3. Accessed 01/13/2019.
Lerman, I. C. (2016). Foundations and methods in combinatorial and statistical data analysis and clustering. Springer London, 2016. https://doi.org/10.1007/978-1-4471-6793-8 .

Malwa, S. (2018). All you need to know about Crypto Airdrops. AKA Free Money. https://hackernoon.com/all-you-need-to-know-aboutcrypto-airdrops-aka-free-money-243e60b22493. Accessed 07/03/ 2019

Masulli, F., \& Rovetta, S. (2012). Clustering high-dimensional data. In Masulli, F., Petrosino, A., Rovetta, S. (Ed.). Clustering HighDimensional Data. First International Workshop, CHDD 2012 Naples, Italy, May 15, 2012.

Mattila, J. and Seppälä, T. (2018). Distributed governance in multi-sided platforms: A conceptual framework from case: Bitcoin. In Smedlund, A., Lindblom, A., Mitronen, L. (Ed.). Collaborative Value Co-creation in the Platform Economy. Translational systems sciences. Volume 11 (pp. 183-205). Springer Nature Singapore Pte Ltd. 2018.

McKie, S. (2017). Investing in tokens and decentralized business models. Learn the details behind this impeding entrepreneurial paradigm shift. https://medium.com/blockchannel/investing-in-tokens-anddecentralized-business-models-e 7629efa5d9b. Accessed 08/22/ 2018

Moore, J. F. (1993). Predators and prey: A new ecology of competition. Harvard Business Review, May 1999. https://hbr.org/1993/05/ predators-and-prey-a-new-ecology-of-competition. Accessed 01/ $13 / 2019$.

Moore, J. F. (1996). The death of competition: Leadership and strategy in the age of business ecosystems. Australia: HarperBusiness.

Morris, M., Schindehutte, M., \& Allen, J. (2005). The entrepreneur's business model: Toward a unified perspective. Journal of Business Research, 58(6), 726-735. https://doi.org/10.1016/j.jbusres.2003. 11.001 .

Mougayar, W. (2017). Tokenomics - A business guide to token usage, utility and value. https://medium.com/@wmougayar/tokenomics-abusiness-guide-to-token-usage-utility-and-value-b19242053416. Accessed 08/22/2018.

Nickerson, R. C., Varshney, U., \& Muntermann, J. (2013). A method for taxonomy development and its application in information systems. European Journal of Information Systems, 22, 336-359. https://doi. org/10.1057/ejis.2012.26 .

Oliveira, L., Zavolokina, L., Bauer, I., \& Schwabe, G. (2018). To token or not to token: Tools for understanding Blockchain tokens, In proceedings of the 39th international conference on information systems (ICIS). San Francisco: CA.

Papert, M., \& Pflaum, A. (2017). Development of an ecosystem model for the realization of internet of things (IoT) Services in Supply Chain Management. 27(2), 175-189, https://doi.org/10.1007/ s12525-017-0251-8.

Park, Y. W. (2018). Business Architecture Strategy and Platform-Based Ecosystems. Springer Nature Singapore Pte Ltd., 2018.

Park, J.-W., \& Yang, S.-B. (2018). An empirical study on factors affecting Blockchain start-ups' fundraising via initial coin offerings, In proceedings of the 39th international conference on information systems (ICIS). San Francisco: CA.

Parker, G. G., Van Alstyne, M. W., Coudary, P. S. (2016). Platform revolution. How networked markets are transformed the economy - and how to make them work for you. $1^{\text {st }}$ edition, New York, W.W. Norton \& Company Inc.

Peltoniemi, M. (2005). Business ecosystem: A conceptual model of an organization population from the perspectives of complexity and evolution, Tampere, Finland: e-BRC Research Reports 18, ISBN 9521513403 .

Peltoniemi, M., \& Vuori, E. (2004). Business ecosystem as the new approach to complex adaptive business environments. In M. Seppä, M. Hannula, A. Järvelin, J. Kujala, M. Ruohonen, \& T. Tiainen (Eds.), Frontiers of e-business research 2004, conference proceedings of 
eBRF 2004, Tampere, Finland: Tampere University of Technology and University of Tampere, ISBN (Vol. 9521513160 , pp. 267-281).

Peters, C., Blohm, I., \& Leimeister, J. M. (2015). Anatomy of successful business models for complex. Services: Insights from the Telemedicine Field. Journal of Management Information Systems, 32(3), 75-104.

Pilkington, M. (2015). Blockchain technology: Principles and applications (September 18, 2015). Research Handbook on Digital Transformations, edited by F. Xavier Olleros and Majlinda Zhegu. Edward Elgar, 2016. Available at SSRN: https://ssrn.com/abstract= 2662660

Remane, G., Nickerson, R., Hanelt, A., Tesch, J. F., \& Kolbe, L. M. (2016). A taxonomy of carsharing business models. Thirty seventh international conference on information systems, Dublin 2016.

Rossignol, M., Lagrange, M., \& Cont, A. (2018). Efficient similaritybased data clustering by optimal object to cluster reallocation. PLoS ONE, public library of science, 2018. https://doi.org/10. 1371/journal.pone.0197450

Salminen, J., Gach, N., Kaartemo, V. (2018). Platform as a social contract: An analytical framework for studying social dynamics in online platforms. pp. 41-64). Translational systems sciences. Volume 11. Springer Nature Singapore Pte Ltd. 2018 https://doi.org/10. 1007/978-981-10-8956-5_3

Selander, L., Henfridsson, O., Svahn, F. (2010). Transforming ecosystem relationships in digital innovation. In proceedings of the international conference on information systems 2010 (ICIS). Paper 138.

Simatupang, T. M. (2007). A taxonomy of supply chain collaboration. Journal of Management Technology. Volume 6 Number 22007 (pp. 304-323), https://doi.org/10.1504/IJVCM.2007.013306 .

Smedlund, A., Faghankhani, H., Ikävalko, H., Turkama, P. (2018). Platform ecosystem orchestration for efficiency, development, and innovation. In Smedlund, A., Lindblom, A., Mitronen, L. (Ed.). Collaborative Value Co-creation in the Platform Economy. Translational Systems Sciences. Volume 11. Springer Nature Singapore Pte Ltd. 2018.

Stummer, C., Kundisch, D., \& Decker, R. (2018). Platform launch strategies. Bus Inf Syst Eng, 60(2), 167-173. https://doi.org/10.1007/ s12599-018-0520-x .
Subramanian, H. (2018). Decentralized Blockchain-based electronic marketplaces. Communications of the ACM. January 2018. Vol. 61. No1. https://doi.org/10.1145/3158333 .

Swan, M. (2015). Blockchain. Blueprint for a new economy. O'Reilly Media, $1^{\text {st }}$ Edition.

Tham, A., Selen, W., Ogulin, R. (2017). Taming the wicked problem of a drone ecosystem: The role of the media. Emergence: Complexity and Organization. Edition 1. https://doi.org/10.17357/ bacc2e084836724ce105044a1486179a.

Theurl, T., Meyer, E. (2019). Cooperatives in the age of sharing. In Riemer, K., Schellhammer, S., Meinert, M. (Ed.). Collaboration in the digital age. How technology enables individuals, teams and businesses. pp.187-205. Springer International Publishing AG. https://doi.org/10.1007/978-3-319-94487-6 9 .

Tönnissen, S., Teuteberg, F. (2018). Using blockchain technology for business processes in purchasing - concept and case study-based evidence. In Abramowicz W., Paschke A. (Ed.) Business Information Systems. BIS 2018. Lecture notes in business information processing, vol 320. Springer, Cham. https://doi.org/10.1007/ 978-3-319-93931-5_18.

Van Alstyne, M. W., Parker, G. G., Choudary, S. P. (2016). Pipelines, platforms, and the new rules of strategy. Harvard Business Review, 2016, pp. 54-60,62.

Ward, J. H. (1963). Hierarchical grouping to optimize an objective function. Journal of the American Statistical Association, 58(301), 236244.

Webster, J., \& Watson, R. T. (2002). Analyzing the past to prepare for the future: Writing a literature review. MIS Quarterly, 26(2), xiii-xxiii.

Wenger, A., (2016). Crypto tokens and the coming age of protocol innovation, https://continuations.com/post/148098927445/cryptotokens-and-the-coming-age-of-protocol. Accessed 06/13/2019.

Publisher's note Springer Nature remains neutral with regard to jurisdictional claims in published maps and institutional affiliations. 